\title{
Assessing teachers' attitude and use of laptops for teaching and learning among primary school mathematics teachers
}

\begin{abstract}
This research explored attitude towards laptops and the use of laptops among primary school mathematics teachers. The State Government granted them personal laptops. This study implemented quantitative study using questionnaires, which were collected from 304 teachers. The findings indicated that the use of laptops for work related and personal use is low. The most favorable work related activity using the laptops was more on searching and preparing for teaching aids while the personal use of laptop was towards updating themselves in current affairs. However, this study found that teachers' attitude towards laptop is positive. Correlational analysis showed that there is a significant relationship between attitude towards laptops and work related $(\mathrm{r}=.406 * *, \mathrm{p}=.001)$ and personal $\mathrm{use}(\mathrm{r}=.276, \mathrm{p}=.001)$. In terms of gender, there is no significance difference between male and female teachers attitudes toward using laptop.
\end{abstract}

Keyword: Attitude towards laptop; Laptop use; Mathematics teachers; Teaching and learning 